\title{
Understanding and engineering alcohol-tolerant bacteria using OMICS technology
}

\author{
Takaaki Horinouchi $^{1}$ [D $\cdot$ Tomoya Maeda $^{1} \cdot$ Chikara Furusawa $^{1,2}$
}

Received: 24 July 2018 / Accepted: 13 October 2018 / Published online: 19 October 2018

(c) The Author(s) 2018

\begin{abstract}
Microbes are capable of producing alcohols, making them an important source of alternative energy that can replace fossil fuels. However, these alcohols can be toxic to the microbes themselves, retaring or inhibiting cell growth and decreasing the production yield. One solution is improving the alcohol tolerance of such alcohol-producing organisms. Advances in omics technologies, including transcriptomic, proteomic, metabolomic, and genomic technologies, have helped us understand the complex mechanisms underlying alcohol toxicity, and such advances could assist in devising strategies for engineering alcohol-tolerant strains. This review highlights these advances and discusses strategies for improving alcohol tolerance using omics analyses.
\end{abstract}

Keywords Adaptive laboratory evolution $\cdot$ Alcohol tolerance $\cdot$ Bacteria $\cdot$ Omics technology

\section{Introduction}

Engineering microorganisms to produce biochemicals has attracted attention as a strategy for reducing the dependency on fossil fuels and developing alternate renewable energy sources. Microbial production of alcohols such as ethanol, propanol, butanol, and other short-chain alcohols has been refined by many researchers (Hanai et al. 2007; Keasling and Chou 2008; Stephanopoulos 2008; Gronenberg et al. 2013). The selection of a microbial production host for an industrial biotechnology process is primarily determined by its potential to efficiently produce the product of interest. Yeast and bacteria are frequently selected as host organisms for bioalcohol production (Lau et al. 2010; Yamamoto et al. 2013). The yeast Saccharomyces cerevisiae is a natural producer of ethanol that has been widely applied for the production of bioethanol. Conversely, bacteria have advantages such as rapid growth, the utilization of various carbon sources, and

Takaaki Horinouchi

takaaki_horinouchi@riken.jp

$\bowtie$ Chikara Furusawa

chikara.furusawa@riken.jp

1 Center for Biosystems Dynamics Research (BDR), RIKEN, 6-2-3 Furuedai, Suita, Osaka 565-0874, Japan

2 Universal Biology Institute, The University of Tokyo, 7-3-1 Hongo, Tokyo 113-0033, Japan the availability of genetic and molecular tools (Rumbold et al. 2009; Koppolu and Vasigala 2016).

In the bioproduction of these alcohols, a major problem is that the toxicity of the alcoholic compounds slows or inhibits cell growth, decreasing the production yield. The alcohol tolerance of bacteria is generally inferior to that of yeast; thus, alcohol toxicity is a more serious problem for bioproduction using bacteria. One strategy to overcome this problem is to develop strains that have tolerance to the target compounds. Thus, it is important to understand the mechanisms underlying alcohol tolerance.

Bacterial alcohol stress response has been studied for more than 40 years, and the physiological effect of alcohol stress has been well described. These studies primarily investigated the mechanisms by which alcoholic compounds affect the bacterial membrane. For example, alcohols interact directly with the lipid bilayer because of their amphiphilicity, and membrane fluidity is altered by the insertion of alcohols into cellular membranes (Ingram 1976). These changes in fluidity increase membrane permeability and induce conformational changes in membrane proteins, and ethanol-induced membrane changes induce the expression of heat-shock and phage-shock proteins (Neidhardt et al. 1984; Brissette et al. 1990). Alcoholic compounds also cause the partial breakdown of membrane function. This membrane damage causes various perturbations to cells such as ion leakage or loss of energy. In this context, many studies have 
focused on the relationship between alcohol tolerance and membrane composition. For example, changes of fatty acid composition (increase in the amount of unsaturated fatty acids) are observed during adaptation to ethanol in Escherichia coli (Ingram 1976; Berger et al. 1980). As another example, modifications of the unsaturated/saturated fatty acid ratio are found in Clostridium acetobutylicum cell membranes during acetone-butanol fermentation (Lepage et al. 1987). Modification of membrane composition via genetic manipulation also confers alcohol tolerance (Grandvalet et al. 2008; Luo et al. 2009). These studies illustrate that modifying the membrane composition can partially mitigate the toxicity of alcohols.

Alcoholic compounds activate various stress response networks (Bury-Moné et al. 2009). For example, the regulatory mechanisms of envelope stress (Ades 2004), oxidative stress (Belkin et al. 1996), and the respiratory cycle (Garbe and Yukawa 2001) are affected by alcohols. These responses are induced by membrane damage and physiological changes of the cellular state (e.g., changes of membrane fluidity, protein misfolding, ion leakage). To establish a rational strategy for improving bacterial alcohol tolerance, it is necessary to understand the cellular activities related to alcohol toxicity. We believe that advances in omics technologies, including transcriptomic, proteomic, metabolomic, and genomic technologies, can help us understand the impact of bacterial alcohol stress.

This review highlights advances in the use of omics technologies to understand alcohol tolerance in bacteria. First, we describe the comprehensive effect of alcohol toxicity using omics technologies. Further, we focus on several approaches for improving alcohol tolerance. We also focus on the alcohol stress response and tolerance of several bacterial species. E. coli has been used for biofuel production by engineering production pathways (Clomburg and Gonzalez 2010; Peralta-Yahya and Keasling 2010), and its well-characterized genetic background and well-developed genetic tools allow for flexible and economical process design for large-scale alcohol production. Likewise, C. acetobutylicum has been used for decades to produce butanol (Jones et al. 1982; Hermann et al. 1985). Most recently, cyanobacteria have attracted attention as promising industrial microorganisms for bioproduction because the cells can directly fix atmospheric carbon dioxide and convert it to a target compound using energy from photosynthesis (Nozzi et al. 2013; Lau et al. 2015). In this study, we review studies on alcohol tolerance in these species with an emphasis on improving alcohol production. Furthermore, to combine omics approaches with recent engineering approaches for strain improvement, it is possible to expand our search for phenotypes of alcohol tolerance (Fig. 1). We describe these promising approaches toward understanding and improving microbial tolerance to alcohol.

\section{Understanding alcohol tolerance using omics technologies}

Alcoholic compounds activate various stress response networks by causing membrane damage. Comprehensive measurements made using omics technologies help us analyze the effect of alcohol stress on cellular states. Several studies provided lists of genes, proteins, and intracellular compounds that participate the alcohol stress response. For example, to screen genes related to this stress response, investigators analyzed gene expression in the presence and absence of
Fig. 1 Strategy for the understanding alcohol-tolerance using omics technologies and recent engineering approaches for strain improvement. Adaptive laboratory evolution (ALE) is an approach for generating cells with improved growth and stress tolerance by mutations and natural selection. Global transcription machinery engineering (gTME) is an approach for obtaining various cellular phenotypes by reprogramming gene transcription using errorprone PCR. To combine omics analyses with these approaches, it is possible to expand our research for phenotypes of alcohol tolerance

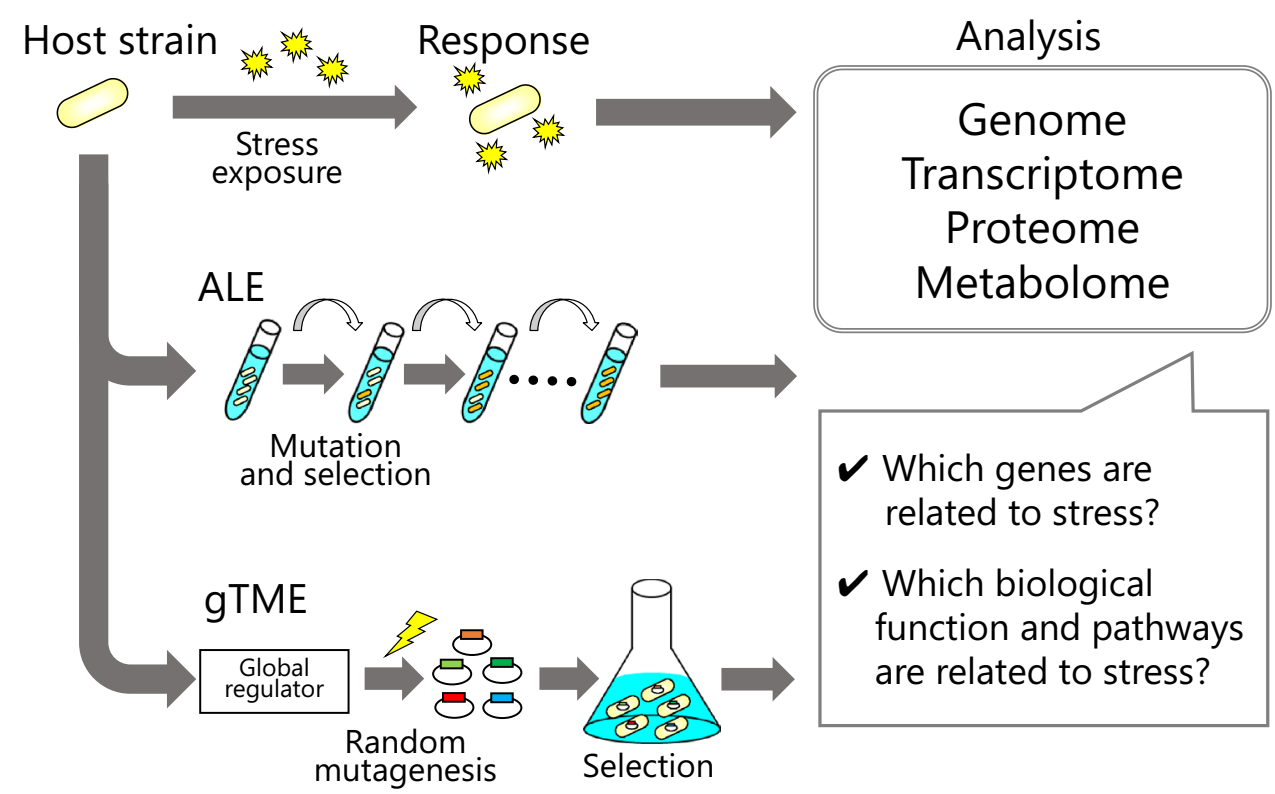


alcohols in the culture medium. These findings should be a starting point for understanding the molecular mechanisms involved in ethanol stress tolerance, and thus, they represent fundamental knowledge for designing ethanol-tolerant cells. Recent studies on the bacterial alcohol stress response are summarized in Table 1.

Transcriptome analyses of $E$. coli under isobutanol stress revealed that cellular functions related to respiration, phosphate metabolism, and iron metabolism were perturbed (Brynildsen and Liao 2009). Further investigation via network component and knockout analyses illustrated that several transcription factors play important roles in the isobutanol response network. This study proposed that the isobutanol stress response is triggered by a malfunction of quinone (Brynildsen and Liao 2009). As another example, transcriptome and proteome analyses of $E$. coli exposed to $n$-butanol demonstrated that this stress activates several stress response machineries simultaneously, including cell envelope stress, oxidative stress, and acid stress responses. This stress also induces protein misfolding and activates efflux systems (Rutherford et al. 2010). These analyses allowed us to identify key genes involved in alleviating oxidative stress, protein misfolding, and other causes of growth defects. The genes and biological activities identified in these studies could be important assets for engineering alcohol-tolerant bacteria.

In E. coli, metabolomic analyses of its responses to ethanol, $n$-butanol, and isobutanol stresses revealed that several amino acids and osmoprotectants, such as isoleucine, valine, glycine, glutamate, and trehalose, are key metabolites that protect against these stresses (Wang et al. 2013). Several transcriptomic studies also demonstrated the relationship between alcohol stress and these low-molecular-weight compounds (Gonzalez et al. 2003; Horinouchi et al. 2010, 2017a; Swings et al. 2017). Although the roles of these compounds in the alcohol stress response remain unclear, they may mitigate the growth inhibition caused by alcohol stress. Further, alcohol can inhibit translation, and this inhibition can be mitigated by the addition of exogenous amino acids or deletion of repressors (Haft et al. 2014). Specifically, Haft et al. (2014) found that ethanol has detrimental effects on translational misreading, ribosome stalling, and the aberrant termination of polypeptide synthesis. They demonstrated that such effects on translation are caused by methionine depletion.

Transcriptomic analyses of $C$. acetobutylicum under $n$-butanol stress identified genes related to the $n$-butanol stress response (Tomas et al. 2003a, b, 2004). These studies identified important roles of the groESL chaperone system and the global regulator of sporulation spoOA. Further analyses suggested that the expression level of genes related to the functional categories of "glycolysis", "amino acid biosynthesis and transport", and "oxidative stress response" are changed by exposure to $n$-butanol stress (Alsaker et al. 2010). Although significant physiological differences exist between $E$. coli and C. acetobutylicum (such as cellular membrane structure, composition, and the ability to form spores), similar functional categories were noted (Alsaker et al. 2010). Although differences of cellular membrane structure strongly affect $n$-butanol tolerance, these similarities of functions response to $n$-butanol suggest that a common mechanism of alcohol toxicity exists between these species.

The alcohol stress responses of Synechocystis sp. have been analyzed using omics technologies since 2010 (summarized in Table 1). Several studies revealed that oxidative stress response is activated by alcohols. For example, transcriptomic analysis of Synechocystis spp. exposed to $n$-butanol demonstrated that oxidative stress responserelated genes were upregulated (Anfelt et al. 2013). As another example, proteomic analysis of Synechocystis revealed that oxidative stress response is induced by ethanol (Qiao et al. 2012). Photosynthetic organisms may be more susceptible to the effects of alcohols because of the sensitivity to the redox state of key molecules such as plastoquinone and the intricate organization of the membrane-bound photosynthetic apparatus. Alleviating oxidative stress is a target for improving the alcohol tolerance of Synechocystis.

\section{Adaptive laboratory evolution (ALE) of alcohol tolerance}

Adaptive laboratory evolution is a powerful tool for analyzing phenotypic and genotypic changes during bacterial evolution (Dragosits and Mattanovich 2013; Winkler and Kao 2014). In this approach, cells are cultured under a selective environment for many generations, leading to adaptive evolution. Then, using omics technologies, we can obtain genome-wide information about adaptive phenotypic and genotypic changes resulting from the selective pressure. Advances in omics technologies, especially decreases in the cost of genome re-sequencing, have made ALE a standard approach for investigating and engineering desired phenotypes and analyzing alcohol tolerance in various microorganisms (summarized in Table 1).

In some cases, different studies identified different genes as contributing to alcohol tolerance even though the studies used the same stressor for ALE experiments. For example, Minty et al. (2011) identified mutations in $m d h$ (malate dehydrogenase) and $r p h$ (defective ribonuclease $\mathrm{PH}$ ) in $E$. coli evolved under isobutanol stress (Minty et al. 2011). However, neither change was found in a study of isobutanoltolerant $E$. coli by Atsumi et al. (2010). Alternatively, mutations in thaA (tryptophanase) and $y h b J$ (renamed as rapZ, RNase adaptor protein) identified by Atsumi et al. (2010) 
Table 1 Omics experiments with bacteria

\begin{tabular}{|c|c|c|c|c|}
\hline Species & Strain & Stress & Analysis & References \\
\hline E. coli & Ethanol-tolerant strain LY01 & Ethanol & Transcriptome & Gonzalez et al. (2003) \\
\hline E. coli & $\begin{array}{l}\text { Transposon library, overex- } \\
\text { pression library }\end{array}$ & Ethanol & Enrichment & Goodarzi et al. (2010) \\
\hline E. coli & Ethanol-evolved strains A-F & Ethanol & Transcriptome & Horinouchi et al. (2010) \\
\hline E. coli & $\begin{array}{l}\text { Mutated IrrE from Deinococ- } \\
\text { cus radiodurans }\end{array}$ & Ethanol & Transcriptome, proteome & Chen et al. (2012) \\
\hline E. coli & Fosmid library & Ethanol & Enrichment & Nicolaou et al. (2012) \\
\hline E. coli & $\operatorname{trans} 10$ & $\begin{array}{l}\text { Ethanol, } n \text {-butanol, Isobu- } \\
\text { tanol }\end{array}$ & Metabolome & Wang et al. (2013) \\
\hline E. coli & Genomic library & Ethanol & $\begin{array}{l}\text { Enrichment analysis, tran- } \\
\text { scriptome, proteome }\end{array}$ & Woodruff et al. (2013) \\
\hline E. coli & $\begin{array}{l}\text { Tolerant strain MTA156, } \\
\text { MTA157, and MTA160 }\end{array}$ & Ethanol & $\begin{array}{l}\text { DNAseq, RNAseq, ribosome } \\
\text { profiling }\end{array}$ & Haft et al. (2014) \\
\hline E. coli & $\begin{array}{l}\text { Genomic library of solvent- } \\
\text { tolerant Lactobacillus } \\
\text { plantarum }\end{array}$ & Ethanol & Enrichment & Zingaro et al. (2014) \\
\hline E. coli & $\begin{array}{l}\text { Metagenomic and heterolo- } \\
\text { gous genomic libraries of } \\
\text { sigma factor }\end{array}$ & Ethanol & Enrichment, transcriptome & Gaida et al. (2015) \\
\hline E. coli & Ethanol-evolved strains A-F & Ethanol & $\begin{array}{l}\text { Genome, transcriptome, } \\
\text { metabolome }\end{array}$ & Horinouchi et al. (2015) \\
\hline E. coli & $\begin{array}{l}\text { High tolerance populations } \\
\text { HT1-16 }\end{array}$ & Ethanol & Genome & Swings et al. (2017) \\
\hline E. coli & Ethanol-tolerant mutant EM & Ethanol & Genome & Chen et al. (2018) \\
\hline E. coli & $\begin{array}{l}\text { Ethanol-tolerant ethanolo- } \\
\text { genic strains }\end{array}$ & Ethanol & Genome & Lupino et al. (2018) \\
\hline E. coli & IPA-tolerant strains A-F & Isopropanol & Genome, transcriptome & Horinouchi et al. (2017a) \\
\hline E. coli & DH1 & $n$-Butanol & Transcriptome, proteome & Rutherford et al. (2010) \\
\hline E. coli & Efflux pump library & $n$-Butanol & Enrichment & Dunlop et al. (2011) \\
\hline E. coli & CRP mutation library & $n$-Butanol & Transcriptome & Lee et al. (2011) \\
\hline E. coli & $\begin{array}{l}\text { Genomic library, overexpres- } \\
\text { sion library }\end{array}$ & $n$-Butanol & Enrichment & Reyes et al. (2011) \\
\hline E. coli & $\begin{array}{l}\text { Adaptive mutants MG1-6 and } \\
\text { MY1-4 }\end{array}$ & $n$-Butanol & Genome, transcriptome & Reyes et al. (2012) \\
\hline E. coli & $\begin{array}{l}\text { Adapted strains B500, G500, } \\
\text { O500, H500, and P500 }\end{array}$ & $n$-Butanol and 3 abiotic stress & $\begin{array}{l}\text { Genome, transcriptome, } \\
\text { cross-stress tolerance }\end{array}$ & Dragosits et al. (2013) \\
\hline E. coli & Transposon library & $n$-Butanol and 12 chemicals & Enrichment, transcriptome & Rau et al. (2016) \\
\hline E. coli & Sigma70 mutant & $n$-Butanol & Transcriptome & Si et al. (2016) \\
\hline E. coli & Fifty-five evolved strains & $n$-Butanol and ten chemicals & $\begin{array}{l}\text { Genome, transcriptome, } \\
\text { cross-stress tolerance }\end{array}$ & Horinouchi et al. (2017b) \\
\hline E. coli & $\begin{array}{l}\text { Butanol-tolerant evolved } \\
\text { strain PKH5000 }\end{array}$ & $n$-Butanol & $\begin{array}{l}\text { Transcriptome, phenotype } \\
\text { microarray }\end{array}$ & Jeong et al. (2017) \\
\hline E. coli & $\begin{array}{l}\text { BW25113 and knockout } \\
\text { strains }\end{array}$ & Isobutanol & Transcriptome & Brynildsen and Liao (2009) \\
\hline E. coli & $\begin{array}{l}\text { Isobutanol-tolerant mutant } \\
\text { SA481 }\end{array}$ & Isobutanol & Genome & Atsumi et al. (2010) \\
\hline E. coli & $\begin{array}{l}\text { Isobutanol-tolerant clone } \\
\text { G3.2, X3.5 }\end{array}$ & Isobutanol & Genome, transcriptome & Minty et al. (2011) \\
\hline E. coli & CRP mutation library & Isobutanol & Transcriptome & Chong et al. (2014) \\
\hline C. acetobutylicum & groESL overexpression strain & $n$-Butanol & Transcriptome & Tomas et al. (2004) \\
\hline C. acetobutylicum & spoOA disrupt mutant & $n$-Butanol & Transcriptome & Tomas et al. (2003a) \\
\hline C. acetobutylicum & groESL overexpression strain & $n$-Butanol & Transcriptome, metabolic flux & Tomas et al. (2003b) \\
\hline C. acetobutylicum & Genomic library & $n$-Butanol & Enrichment & $\begin{array}{l}\text { Borden and Papoutsakis } \\
\text { (2007) }\end{array}$ \\
\hline
\end{tabular}


Table 1 (continued)

\begin{tabular}{|c|c|c|c|c|}
\hline Species & Strain & Stress & Analysis & References \\
\hline C. acetobutylicum & ATCC824 & $n$-Butanol, butyrate, acetate & Transcriptome & Alsaker et al. (2010) \\
\hline C. acetobutylicum & Butanol-tolerant mutant Rh8 & n-Butanol & Proteome & Mao et al. (2010) \\
\hline C. acetobutylicum & DSM1731 & n-Butanol & Proteome & Jia et al. (2012) \\
\hline C. acetobutylicum & Butanol-tolerant mutant Rh8 & n-Butanol & Genome, proteome & Bao et al. (2014) \\
\hline C. acetobutylicum & ATCC824 & n-Butanol & Metabolome & Wang et al. (2016) \\
\hline C. acetobutylicum & $\begin{array}{l}\text { Butanol-tolerant asporogenic } \\
\text { strain JB200 }\end{array}$ & n-Butanol & Genome & Xu et al. (2017) \\
\hline Synechocystis & sp. PCC 6803 & Ethanol & Proteome & Qiao et al. (2012) \\
\hline Synechocystis & $\Delta s l l 0794$ & Ethanol & Proteome & Song et al. (2014) \\
\hline Synechocystis & sp. PCC 6803 & Ethanol & Metabolome & Zhu et al. (2015) \\
\hline Synechocystis & sp. PCC 6803 & $\begin{array}{l}\text { Ethanol, } n \text {-butanol, hexane, } \\
\text { salt }\end{array}$ & sRNA-seq & Pei et al. (2017) \\
\hline Synechocystis & $\begin{array}{l}\text { Recombinant strains UL } 004 \\
\text { and UL } 030\end{array}$ & Ethanol & Flow cytometry & Lopes da Silva et al. (2018) \\
\hline Synechocystis & Tolerant mutant SY1043 & Isopropanol & Genome, single-cell screening & Hirokawa et al. (2018) \\
\hline Synechocystis & sp. PCC 6803 & $n$-Butanol & Transcriptome & Anfelt et al. (2013) \\
\hline Synechocystis & Evolved strain S1, S3, S4 & n-Butanol & Metabolome & Wang et al. (2014) \\
\hline Synechocystis & $\Delta$ slr1037 mutant & n-Butanol & Metabolome & Niu et al. (2015) \\
\hline Synechocystis & Evolved strain T(1)-T(4) & Isobutanol & Genome & Matsusako et al. (2017) \\
\hline
\end{tabular}

were not identified by Minty et al. (2011). These discordances may be caused by differences in experimental conditions, such as the parental strain, culture conditions, and selective pressure. Another possible cause is the diversity of the obtained alcohol-tolerant strains. Many different mutations are often acquired among the evolved strains obtained via multiple ALEs under the same experimental conditions. It is important to verify whether the identified mutations contribute to alcohol tolerance.

When bacterial cells become tolerant to one stress via ALE, they sometimes also become more tolerant to other stresses, a phenomenon called cross protection. However, they sometimes become more sensitive to other stresses, a phenomenon called collateral sensitivity. These scenarios provide valuable information regarding the mechanisms of stress tolerance. Notably, the existence of cross protection and collateral sensitivity among $n$-butanol and other abiotic stresses, such as acid stress, hyperosmotic stress, oxidative stress, and alkali stress, has been identified (Dragosits et al. 2013; Reyes et al. 2013; Horinouchi et al. 2017b). For example, an $n$-butanol-tolerant strain obtained by Dragosits et al. (2013) also exhibited tolerance to $\mathrm{NaCl}$ and low pH. This study found that mutations in iron-related genes represent a common genetic factor that drives bacterial tolerance across multiple stresses. Such cross-stress observations are important because they can provide insight into the pleiotropic effects of alcohol on cellular functions.

In addition to cross-stress behavior, the acquisition of stress tolerance in bacterial cells is sometimes accompanied by "fitness cost", a reduction of fitness (growth or viability in this case) in the absence of stress. This phenomenon is well studied in the field of antibiotic resistance in bacteria (Lenski 1998; Andersson and Hughes 2010). Fitness in the absence of stress is important for biofuel production and alcohol tolerance. One possible approach to overcoming this problem is improving fitness in the culture condition (e.g., medium, temperature, scale of culture), which is not dependent on the presence or absence of alcohol stress. Several studies demonstrated the improvement the fitness in the absence of alcohol stress via ALE (Conrad et al. 2010; Jiang et al. 2012; Zhao et al. 2013).

\section{Engineering alcohol tolerance}

Based on information about target genes and metabolites obtained via omics analyses, it is possible to rationally engineer alcohol-tolerant bacterial strains. As described previously, several reports noted a relationship between alcohol tolerance and specific amino acids (Gonzalez et al. 2003; Horinouchi et al. 2010, 2017a; Wang et al. 2013; Haft et al. 2014). Based on these results, several groups investigated the biosynthesis or supplementation of these amino acids for improving alcohol tolerance (Gonzalez et al. 2003; Horinouchi et al. 2010, 2017a; Haft et al. 2014). In addition, it is possible to identify mutations that contribute to alcohol tolerance via genome re-sequencing analyses of tolerant strains obtained using ALE, and it is possible to evaluate the effects of specific mutations on alcohol tolerance using genome-editing technology (Pósfai et al. 1999; Wang et al. 
2009; Jiang et al. 2013). Indeed, there are many examples in which alcohol tolerance has been improved by introducing mutations identified by ALE and genome re-sequencing into the genome (Atsumi et al. 2010; Minty et al. 2011; Reyes et al. 2012; Dragosits et al. 2013; Horinouchi et al. 2015, $2017 \mathrm{a}, \mathrm{b})$.

Another approach for improving alcohol tolerance is the heterologous expression of beneficial genes in a host strain. For example, overexpressing the GroESL chaperone from C. acetobutylicum (Abdelaal et al. 2015) in E. coli enhances alcohol tolerance, most likely by stabilizing or refolding proteins that are crucial for cell metabolism and survival. Overexpressing the phasin polyhydroxyalkanoate granuleassociated protein (PhaP) from Azotobacter sp. strain FA8 (Mezzina et al. 2017) in E. coli also enhances alcohol tolerance PhaP from Azotobacter has chaperone activity and exerts a stress-alleviating effect in recombinant $E$. coli cells (de Almeida et al. 2011; Mezzina et al. 2015). In these approaches, beneficial genes associated with alcohol tolerance (e.g., GroESL or PhaP) were found in known alcoholtolerant species such as $C$. acetobutylicum or Azotobacter spp. The advancement of genome sequencing technology will provide useful information about the genetic resources of various microbial species.

A tool called global transcription machinery engineering (gTME) was developed for improving cellular phenotypes (Alper and Stephanopoulos 2007). In this approach, random mutagenesis libraries of global transcription factors are generated by error-prone PCR to reprogram transcription and obtain various phenotypes. The mixture of libraries is cultured in the presence of a stressor to enrich for stress-tolerant mutants. Via this approach, alcohol tolerance was increased in $E$. coli by modifying the RNA polymerase sigma factor $\sigma 70$ (Alper and Stephanopoulos 2007) and cAMP receptor protein (CRP) (Chong et al. 2013). Chong et al. (2014) performed transcriptomic analyses of CRP-engineered mutants and single-gene knockout experiments to characterize the functions of genes related to alcohol tolerance. They demonstrated that $\mathrm{GadX}$ (regulator of acid resistance system), HdeB (periplasmic acid stress chaperone), and several other genes were associated with isobutanol resistance (Chong et al. 2014). They also observed that the intracellular reactive oxygen species level was lower in the engineered mutants than in control strain when facing stress. These results indicated that the engineered mutants can withstand toxic isobutanol much better than the control strain.

\section{Concluding remarks}

The development of omics technologies has undoubtedly facilitated new insights into the mechanisms by which microorganisms tolerate alcohol. For example, recent studies using omics technologies demonstrated that biological functions and response networks related to intracellular redox states are involved in alcohol stress in several microorganisms. These biological functions could be important assets for engineering alcohol-tolerant bacteria. Although alcoholtolerant strains have been engineered, the impact of alcohol stress at the whole-cell level is not fully understood. Such an understanding is complicated by the fact that various cellular functions are undoubtedly related to the toxicity of alcohols; likewise, controlling the biological functions related to alcohol tolerance will likely be complicated. We reason that valuable information will continue to be generated using omics technology. Although omics technologies provide new biological functions that may be related to alcohol tolerance, it is necessary to verify whether these biological functions contribute to alcohol tolerance.

Further, by combining omics approaches with ALE and gTME, we can expand our search for the phenotypes of alcohol tolerance. This will accelerate the research process by identifying novel genes, proteins, or biological functions related to alcohol tolerance. We expect that further developments in the omics space and novel methodologies will allow us to further characterize the mechanisms of alcohol tolerance.

Acknowledgements This work was supported in part by Japan Society for the Promotion of Science KAKENHI Grants number JP17K15052 and JP18H04807.

Open Access This article is distributed under the terms of the Creative Commons Attribution 4.0 International License (http://creativeco mmons.org/licenses/by/4.0/), which permits unrestricted use, distribution, and reproduction in any medium, provided you give appropriate credit to the original author(s) and the source, provide a link to the Creative Commons license, and indicate if changes were made.

\section{References}

Abdelaal AS, Ageez AM, Abd El-Hadi AEHA, Abdallah NA (2015) Genetic improvement of $n$-butanol tolerance in Escherichia coli by heterologous overexpression of groESL operon from Clostridium acetobutylicum. 3 Biotech 5:401-410. https://doi.org/10.1007/ s13205-014-0235-8

Ades SE (2004) Control of the alternative sigma factor $\sigma^{\mathrm{E}}$ in Escherichia coli. Curr Opin Microbiol 7:157-162. https://doi. org/10.1016/j.mib.2004.02.010

Alper H, Stephanopoulos G (2007) Global transcription machinery engineering: a new approach for improving cellular phenotype. Metab Eng 9:258-267. https://doi.org/10.1016/j.ymben .2006 .12 .002

Alsaker KV, Paredes C, Papoutsakis ET (2010) Metabolite stress and tolerance in the production of biofuels and chemicals: geneexpression-based systems analysis of butanol, butyrate, and acetate stresses in the anaerobe Clostridium acetobutylicum. Biotechnol Bioeng 105:1131-1147. https://doi.org/10.1002/bit.22628 
Andersson DI, Hughes D (2010) Antibiotic resistance and its cost: is it possible to reversein resistance? Nat Rev Microbiol 8:260-271. https://doi.org/10.1038/nrmicro2319

Anfelt J, Hallström B, Nielsen J et al (2013) Using transcriptomics to improve butanol tolerance of Synechocystis sp. strain PCC 6803. Appl Environ Microbiol 79:7419-7427. https://doi.org/10.1128/ AEM.02694-13

Atsumi S, Wu T-Y, Machado IMP et al (2010) Evolution, genomic analysis, and reconstruction of isobutanol tolerance in Escherichia coli. Mol Syst Biol 6:449. https://doi.org/10.1038/msb.2010.98

Bao G, Dong H, Zhu Y et al (2014) Comparative genomic and proteomic analyses of Clostridium acetobutylicum Rh8 and its parent strain DSM 1731 revealed new understandings on butanol tolerance. Biochem Biophys Res Commun 450:1612-1618. https://doi.org/10.1016/j.bbrc.2014.07.052

Belkin S, Smulski DR, Vollmer AC et al (1996) Oxidative stress detection with Escherichia coli harboring a katG: lux fusion. Appl Environ Microbiol 62:2252-2256

Berger B, Carty CE, Ingram LO (1980) Alcohol-induced changes in the phospholipid molecular species of Escherichia coli. J Bacteriol 142:1040-1044

Borden JR, Papoutsakis ET (2007) Dynamics of genomic-library enrichment and identification of solvent tolerance genes for Clostridium acetobutylicum. Appl Environ Microbiol 73:30613068. https://doi.org/10.1128/AEM.02296-06

Brissette JL, Russel M, Weiner L, Model P (1990) Phage shock protein, a stress protein of Escherichia coli. Proc Natl Acad Sci USA 87:862-866. https://doi.org/10.1073/pnas.87.3.862

Brynildsen MP, Liao JC (2009) An integrated network approach identifies the isobutanol response network of Escherichia coli. Mol Syst Biol 5:277. https://doi.org/10.1038/msb.2009.34

Bury-Moné S, Nomane Y, Reymond N et al (2009) Global analysis of extracytoplasmic stress signaling in Escherichia coli. PLoS Genet 5:e1000651. https://doi.org/10.1371/journal.pgen.10006 51

Chen T, Wang J, Zeng L et al (2012) Significant rewiring of the transcriptome and proteome of an Escherichia coli strain harboring a tailored exogenous global regulator irre. PLoS One 7:e371126. https://doi.org/10.1371/journal.pone.0037126

Chen Y, Wang Y, Chen TH et al (2018) Identification and manipulation of a novel locus to improve cell tolerance to short-chain alcohols in Escherichia coli. J Ind Microbiol Biotechnol 45:589-598. https ://doi.org/10.1007/s10295-017-1996-y

Chong H, Huang L, Yeow J et al (2013) Improving ethanol tolerance of Escherichia coli by rewiring Its global regulator cAMP receptor protein (CRP). PLoS One 8:e57628. https://doi.org/10.1371/ journal.pone.0057628

Chong H, Geng H, Zhang H et al (2014) Enhancing E. coli isobutanol tolerance through engineering its global transcription factor cAMP receptor protein (CRP). Biotechnol Bioeng 111:700-708. https://doi.org/10.1002/bit.25134

Clomburg JM, Gonzalez R (2010) Biofuel production in Escherichia coli: the role of metabolic engineering and synthetic biology. Appl Microbiol Biotechnol 86:419-434

Conrad TM, Frazier M, Joyce AR et al (2010) RNA polymerase mutants found through adaptive evolution reprogram Escherichia coli for optimal growth in minimal media. Proc Natl Acad Sci USA 107:20500-20505. https://doi.org/10.1073/pnas.0911253107

de Almeida A, Catone MV, Rhodius VA et al (2011) Unexpected stress-reducing effect of PhaP, a poly(3-hydroxybutyrate) granuleassociated protein, in Escherichia coli. Appl Environ Microbiol 77:6622-6629. https://doi.org/10.1128/AEM.05469-11

Dragosits M, Mattanovich D (2013) Adaptive laboratory evolutionprinciples and applications for biotechnology. Microb Cell Fact 12:64. https://doi.org/10.1186/1475-2859-12-64
Dragosits M, Mozhayskiy V, Quinones-Soto S et al (2013) Evolutionary potential, cross-stress behavior and the genetic basis of acquired stress resistance in Escherichia coli. Mol Syst Biol 9:643. https://doi.org/10.1038/msb.2012.76

Dunlop MJ, Dossani ZY, Szmidt HL et al (2011) Engineering microbial biofuel tolerance and export using efflux pumps. Mol Syst Biol 7:487. https://doi.org/10.1038/msb.2011.21

Gaida SM, Sandoval NR, Nicolaou SA et al (2015) Expression of heterologous sigma factors enables functional screening of metagenomic and heterologous genomic libraries. Nat Commun 6:7045. https://doi.org/10.1038/ncomms8045

Garbe TR, Yukawa H (2001) Common solvent toxicity: autoxidation of respiratory redox-cyclers enforced by membrane derangement. Zeitschrift fur Naturforsch - Sect C J Biosci 56:483-491

Gonzalez R, Tao H, Purvis JE et al (2003) Gene array-based identification of changes that contribute to ethanol tolerance in ethanologenic Escherichia coli: comparison of KO11 (parent) to LY01 (resistant mutant). Biotechnol Prog 19:612-623. https:// doi.org/10.1021/bp025658q

Goodarzi H, Bennett BD, Amini S et al (2010) Regulatory and metabolic rewiring during laboratory evolution of ethanol tolerance in E. coli. Mol Syst Biol 6:378. https://doi.org/10.1038/ msb. 2010.33

Grandvalet C, Assad-García JS, Chu-Ky S et al (2008) Changes in membrane lipid composition in ethanol- and acid-adapted Oenococcus oeni cells: characterization of the $c f a$ gene by heterologous complementation. Microbiology 154:2611-2619. https ://doi.org/10.1099/mic.0.2007/016238-0

Gronenberg LS, Marcheschi RJ, Liao JC (2013) Next generation biofuel engineering in prokaryotes. Curr Opin Chem Biol 17:462471. https://doi.org/10.1016/j.cbpa.2013.03.037

Haft RJF, Keating DH, Schwaegler T et al (2014) Correcting direct effects of ethanol on translation and transcription machinery confers ethanol tolerance in bacteria. Proc Natl Acad Sci 111:E2576-E2585. https://doi.org/10.1073/pnas.1401853111

Hanai T, Atsumi S, Liao JC (2007) Engineered synthetic pathway for isopropanol production in Escherichia coli. Appl Environ Microbiol 73:7814-7818. https://doi.org/10.1128/AEM.01140 $-07$

Hermann M, Fayolle F, Marchal R et al (1985) Isolation and characterization of butanol-resistant mutants of Clostridium acetobutylicum. Appl Environ Microbiol 50:1238-1243

Hirokawa Y, Kanesaki Y, Arai S et al (2018) Mutations responsible for alcohol tolerance in the mutant of Synechococcus elongatus PCC 7942 (SY1043) obtained by single-cell screening system. J Biosci Bioeng 125:572-577. https://doi.org/10.1016/j.jbiosc.2017.11.012

Horinouchi T, Tamaoka K, Furusawa C et al (2010) Transcriptome analysis of parallel-evolved Escherichia coli strains under ethanol stress. BMC Genom 11:579

Horinouchi T, Suzuki S, Hirasawa T et al (2015) Phenotypic convergence in bacterial adaptive evolution to ethanol stress. BMC Evol Biol 15:180

Horinouchi T, Sakai A, Kotani H et al (2017a) Improvement of isopropanol tolerance of Escherichia coli using adaptive laboratory evolution and omics technologies. J Biotechnol 255:47-56. https ://doi.org/10.1016/j.jbiotec.2017.06.408

Horinouchi T, Suzuki S, Kotani H et al (2017b) Prediction of crossresistance and collateral sensitivity by gene expression profiles and genomic mutations. Sci Rep 7:14009. https://doi.org/10.1038/ s41598-017-14335-7

Ingram LO (1976) Adaptation of membrane lipids to alcohols. J Bacteriol 125:670-678

Jeong H, Lee SW, Kim SH et al (2017) Global functional analysis of butanol-sensitive Escherichia coli and its evolved butanol-tolerant strain. J Microbiol Biotechnol 27:1171-1179. https://doi. org/10.4014/jmb.1702.02021 
Jia K, Zhang Y, Li Y (2012) Identification and characterization of two functionally unknown genes involved in butanol tolerance of clostridium acetobutylicum. PLoS One 7:e388115. https://doi. org/10.1371/journal.pone.0038815

Jiang L, Li S, Hu Y et al (2012) Adaptive evolution for fast growth on glucose and the effects on the regulation of glucose transport system in Clostridium tyrobutyricum. Biotechnol Bioeng 109:708718. https://doi.org/10.1002/bit.23346

Jiang W, Bikard D, Cox D et al (2013) RNA-guided editing of bacterial genomes using CRISPR-Cas systems. Nat Biotechnol 31:233-239. https://doi.org/10.1038/nbt.2508

Jones DT, Van Der Westhuizen A, Long S (1982) Solvent production and morphological changes in Clostridium acetobutylicum. Appl Environ Microbiol 43:1434-1439

Keasling JD, Chou H (2008) Metabolic engineering delivers nextgeneration biofuels. Nat Biotechnol 26:298-299. https://doi. org/10.1038/ng.85

Koppolu V, Vasigala VK (2016) Role of Escherichia coli in biofuel production. Microbiol Insights 9:MBI.S10878. https://doi. org/10.4137/MBI.S10878

Lau MW, Gunawan C, Balan V, Dale BE (2010) Comparing the fermentation performance of Escherichia coli KO11, Saccharomyces cerevisiae 424A(LNH-ST) and Zymomonas mobilis AX101 forcellulosic ethanol production. Biotechnol Biofuels 3:11-20

Lau NS, Matsui M, Abdullah AAA (2015) Cyanobacteria: photoautotrophic microbial factories for the sustainable synthesis of industrial products. Biomed Res Int 2015:1-9. https://doi. org/10.1155/2015/754934

Lee JY, Yang KS, Jang SA et al (2011) Engineering butanol-tolerance in Escherichia coli with artificial transcription factor libraries. Biotechnol Bioeng 108:742-749. https://doi.org/10.1002/ bit.22989

Lenski RE (1998) Bacterial evolution and the cost of antibiotic resistance. Int Microbiol 1:265-270. https://doi.org/10.2436/im.v1i4.27

Lepage C, Fayolle F, Hermann M, Vandecasteele J-P (1987) Changes in membrane lipid composition of Clostridium acetobutylicum during acetone-butanol fermentation: effects of solvents, growth temperature and $\mathrm{pH}$. Microbiology 133:103-110. https://doi. org/10.1099/00221287-133-1-103

Lopes da Silva T, Passarinho PC, Galriça R et al (2018) Evaluation of the ethanol tolerance for wild and mutant Synechocystis strains by flow cytometry. Biotechnol Rep 17:137-147. https://doi. org/10.1016/j.btre.2018.02.005

Luo LH, Seo PS, Seo JW et al (2009) Improved ethanol tolerance in Escherichia coli by changing the cellular fatty acids composition through genetic manipulation. Biotechnol Lett 31:1867-1871. https://doi.org/10.1007/S10529-009-0092-4

Lupino KM, Romano KA, Simons MJ et al (2018) A recurrent silent mutation implicates $\mathrm{fecA}$ in ethanol tolerance by Escherichia coli. BMC Microbiol 18:36. https://doi.org/10.1186/s1286 6-018-1180-1

Mao S, Luo Y, Zhang T et al (2010) Proteome reference map and comparative proteomic analysis between a wild type Clostridium acetobutylicum DSM 1731 and its mutant with enhanced butanol tolerance and butanol yield. J Proteome Res 9:3046-3061. https ://doi.org/10.1021/pr9012078

Matsusako T, Toya Y, Yoshikawa K, Shimizu H (2017) Identification of alcohol stress tolerance genes of Synechocystis sp. PCC 6803 using adaptive laboratory evolution. Biotechnol Biofuels 10:307. https://doi.org/10.1186/s13068-017-0996-5

Mezzina MP, Wetzler DE, de Almeida A et al (2015) A phasin with extra talents: a polyhydroxyalkanoate granule-associated protein has chaperone activity. Environ Microbiol 17:1765-1776. https:// doi.org/10.1111/1462-2920.12636

Mezzina MP, Álvarez DS, Egoburo DE et al (2017) A new player in the biorefineries field: phasin PhaP enhances tolerance to solvents and boosts ethanol and 1,3-propanediol synthesis in Escherichia coli. Appl Environ Microbiol. https://doi.org/10.1128/AEM.00662-17

Minty JJ, Lesnefsky A, Lin F et al (2011) Evolution combined with genomic study elucidates genetic bases of isobutanol tolerance in Escherichia coli. Microb Cell Fact 10:18. https://doi. org/10.1186/1475-2859-10-18

Neidhardt FC, VanBogelen RA, Vaughn V (1984) The genetics and regulation of heat-shock proteins. Annu Rev Genet 18:295-329

Nicolaou SA, Gaida SM, Papoutsakis ET (2012) Exploring the combinatorial genomic space in Escherichia coli for ethanol tolerance. Biotechnol J 7:1337-1345. https://doi.org/10.1002/biot.20120 0227

Niu X, Zhu Y, Pei G et al (2015) Elucidating butanol tolerance mediated by a response regulator Sll0039 in Synechocystis sp. PCC 6803 using a metabolomic approach. Appl Microbiol Biotechnol 99:1845-1857. https://doi.org/10.1007/s00253-015-6374-y

Nozzi NE, Oliver JWK, Atsumi S (2013) Cyanobacteria as a platform for biofuel production. Front Bioeng Biotechnol 1:7. https ://doi.org/10.3389/fbioe.2013.00007

Pei G, Sun T, Chen S et al (2017) Systematic and functional identification of small non-coding RNAs associated with exogenous biofuel stress in cyanobacterium Synechocystis sp. PCC 6803. Biotechnol Biofuels 10:57. https://doi.org/10.1186/s1306 8-017-0743-y

Peralta-Yahya PP, Keasling JD (2010) Advanced biofuel production in microbes. Biotechnol J 5:147-162. https://doi.org/10.1002/ biot. 200900220

Pósfai G, Kolisnychenko V, Bereczki Z, Blattner FR (1999) Markerless gene replacement in Escherichia coli stimulated by a doublestrand break in the chromosome. Nucleic Acids Res 27:44094415. https://doi.org/10.1093/nar/27.22.4409

Qiao J, Wang J, Chen L et al (2012) Quantitative iTRAQ LC-MS/ MS proteomics reveals metabolic responses to biofuel ethanol in cyanobacterial Synechocystis sp. PCC 6803. J Proteome Res 11:5286-5300. https://doi.org/10.1021/pr300504w

Rau MH, Calero P, Lennen RM et al (2016) Genome-wide Escherichia coli stress response and improved tolerance towards industrially relevant chemicals. Microb Cell Fact 15:176. https://doi. org/10.1186/s12934-016-0577-5

Reyes LH, Almario MP, Kao KC (2011) Genomic library screens for genes involved in $n$-butanol tolerance in Escherichia coli. PLoS One 6:e17678. https://doi.org/10.1371/journal.pone.0017678

Reyes LH, Almario MP, Winkler J et al (2012) Visualizing evolution in real time to determine the molecular mechanisms of $n$-butanol tolerance in Escherichia coli. Metab Eng 14:579-590. https://doi. org/10.1016/j.ymben.2012.05.002

Reyes LH, Abdelaal AS, Kao KC (2013) Genetic determinants for $n$-butanol tolerance in evolved Escherichia coli mutants: cross adaptation and antagonistic pleiotropy between $n$-butanol and other stressors. Appl Environ Microbiol 79:5313-5320. https:// doi.org/10.1128/AEM.01703-13

Rumbold K, Van Buijsen H, Overkamp K et al (2009) Microbial production host selection for converting second generation feedstocks into bioproducts. Microb Cell Fact 8:64-64. https://doi. org/10.1186/1475-2859-8-64

Rutherford BJ, Dahl RH, Price RE et al (2010) Functional genomic study of exogenous $n$-butanol stress in Escherichia coli. Appl Environ Microbiol 76:1935-1945. https://doi.org/10.1128/ AEM.02323-09

Si HM, Zhang F, Wu AN et al (2016) DNA microarray of global transcription factor mutant reveals membrane-related proteins involved in $n$-butanol tolerance in Escherichia coli. Biotechnol Biofuels 9:114. https://doi.org/10.1186/s13068-016-0527-9

Song Z, Chen L, Wang J et al (2014) A transcriptional regulator sll0794 regulates tolerance to biofuel ethanol in photosynthetic 
Synechocystis sp. PCC 6803. Mol Cell Proteom 13:3519-3532. https://doi.org/10.1074/mcp.M113.035675

Stephanopoulos G (2008) Metabolic engineering: enabling technology for biofuels production. Metab Eng 10:293-294

Swings T, Weytjens B, Schalck T et al (2017) Network-based identification of adaptive pathways in evolved ethanol-tolerant bacterial populations. Mol Biol Evol 34:2927-2943. https://doi. org $/ 10.1093 / \mathrm{molbev} / \mathrm{msx} 228$

Tomas CA, Alsaker KV, Bonarius HPJ et al (2003a) DNA arraybased transcriptional analysis of asporogenous, nonsolventogenic Clostridium acetobutylicum strains SKO1 and M5. J Bacteriol 185:4539-4547. https://doi.org/10.1128/ JB.185.15.4539-4547.2003

Tomas CA, Welker NE, Papoutsakis ET (2003b) Overexpression of groESL in Clostridium acetobutylicum results in increased solvent production and tolerance, prolonged metabolism, and changes in the cell's transcriptional program. Appl Environ Microbiol 69:4951-4965. https://doi.org/10.1128/ AEM.69.8.4951-4965.2003

Tomas CA, Beamish J, Papoutsakis ET (2004) Transcriptional analysis of butanol stress and tolerance in Clostridium acetobutylicum. J Bacteriol 186:2006-2018. https://doi.org/10.1128/ JB.186.7.2006-2018.2004

Wang HH, Isaacs FJ, Carr PA et al (2009) Programming cells by multiplex genome engineering and accelerated evolution. Nature 460:894-898. https://doi.org/10.1038/nature08187

Wang J, Chen L, Tian X et al (2013) Global metabolomic and network analysis of Escherichia coli responses to exogenous biofuels. J Proteome Res 12:5302-5312. https://doi.org/10.1021/pr400640u

Wang Y, Shi M, Niu X et al (2014) Metabolomic basis of laboratory evolution of butanol tolerance in photosynthetic Synechocystis sp. PCC 6803. Microb Cell Fact 13:151. https://doi.org/10.1186/ s12934-014-0151-y
Wang YF, Tian J, Ji ZH et al (2016) Intracellular metabolic changes of Clostridium acetobutylicum and promotion to butanol tolerance during biobutanol fermentation. Int J Biochem Cell Biol 78:297306. https://doi.org/10.1016/j.biocel.2016.07.031

Winkler JD, Kao KC (2014) Recent advances in the evolutionary engineering of industrial biocatalysts. Genomics 104:406-411. https ://doi.org/10.1016/j.ygeno.2014.09.006

Woodruff LBA, Pandhal J, Ow SY et al (2013) Genome-scale identification and characterization of ethanol tolerance genes in Escherichia coli. Metab Eng 15:124-133. https://doi.org/10.1016/j.ymben .2012 .10 .007

Xu M, Zhao J, Yu L, Yang ST (2017) Comparative genomic analysis of Clostridium acetobutylicum for understanding the mutations contributing to enhanced butanol tolerance and production. J Biotechnol 263:36-44. https://doi.org/10.1016/j.jbiotec.2017.10.010

Yamamoto S, Suda M, Niimi S et al (2013) Strain optimization for efficient isobutanol production using Corynebacterium glutamicum under oxygen deprivation. Biotechnol Bioeng 110:2938-2948. https://doi.org/10.1002/bit.24961

Zhao J, Xu L, Wang Y et al (2013) Homofermentative production of optically pure L-lactic acid from xylose by genetically engineered Escherichia coli B. Microb Cell Fact 12:1. https://doi. org/10.1186/1475-2859-12-57

Zhu Y, Pei G, Niu X et al (2015) Metabolomic analysis reveals functional overlapping of three signal transduction proteins in regulating ethanol tolerance in cyanobacterium Synechocystis sp. PCC 6803. Mol Biosyst 11:770-782. https://doi.org/10.1039/C4MB0 $0651 \mathrm{H}$

Zingaro KA, Nicolaou SA, Yuan Y, Papoutsakis ET (2014) Exploring the heterologous genomic space for building, stepwise, complex, multicomponent tolerance to toxic chemicals. ACS Synth Biol 3:476-486. https://doi.org/10.1021/sb400156v 